\title{
An economic order quantity model for deteriorating products having stock dependent demand with trade credit period and preservation technology
}

\author{
S. R. Singha ${ }^{a}$ Deepa Khurana ${ }^{b}$ and Shilpy Tayal ${ }^{a *}$
}

${ }^{a}$ Department of Mathematics, C.C.S. University, Meerut, India

${ }^{b}$ Department of Mathematics, Banasthali University, Banasthali, Rajasthan, India

\section{H R O N I C L E}

\begin{tabular}{l}
\hline Article history: \\
Received April 20, 2015 \\
Received in revised format May \\
10, 2015 \\
Accepted August 82015 \\
Available online \\
August 112015 \\
\hline Keywords: \\
Deterioration \\
Stock dependent demand \\
Permissible delay \\
Partial backlogging \\
Preservation technology
\end{tabular}

\begin{abstract}
A B S T R A C T
The objective of this study is to develop of an inventory policy for deteriorating items, in which demand for the products is stock dependent and the retailer invests in preservation technology to reduce the rate of product deterioration. In many real-life situations, for certain types of consumer goods, the consumption rate is sometimes influenced by the stock-level. It is usually observed that a large pile of goods on a shelf in a supermarket will lead the customer to buy more and then generate higher demand. The consumption rate may go up or down with the onhand stock level. This paper is developed with the realistic conditions of demand, allowable credit period, partial backlogging and variable ordering cost. A solution procedure is given to find the optimal preservation technology cost and total cost of the system. A numerical example and sensitivity analysis are presented to illustrate the model.
\end{abstract}

(C) 2016 Growing Science Ltd. All rights reserved.

\section{Introduction}

In today's era of globalization the displayed stock level is a promotional tool to increase the revenue. Many evidences indicate that the presence of a larger quantity of sales items displayed may absorb more customers. This shows that the demand may have a positive correlation with stock level. In many real-life circumstances, for certain kinds of consumer goods, the consumption rate is sometimes affected by the stock-level. Large amounts of consumer goods displayed in a supermarket are normally associated with on sale items to create more sales and profits. However, low stocks of certain baked products might raise the impression that they are not fresh. For instance, if someone intends to buy any fashion garment and got a limited stock then the probability of sale will decrease and on other side if the shopkeeper has the enough stock to display, then demand will increase. Taking into consideration Singh and Singh (2008) presented an inventory model for decaying items with stock-dependent demand under inflation in a supply chain and find the optimal ordering quantity. Singh et al. (2010) introduced an inventory replenishment policy for non-instantaneous deteriorating items with stock-dependent demand and partial backlogging under inflationary environment. Singh and Singh (2012) developed an economic production quantity (EPQ) model with power form stock dependent demand under 
inflationary environment using genetic algorithm. Tyagi et al. (2014) came forward with an optimal replenishment policy for non-instantaneous deteriorating items with stock dependent demand and variable holding cost. An inventory system with multi variate demand under volume flexibility and learning was presented by Singhal and Singh (2015).

During the last decade, many researchers worked on the inventory model with the assumptions that the products have infinite life time, but this does not hold in real-world circumstances. Most of all products are observed to be deteriorating in nature. The quality and quantity of the product may decrease with the increment in time during a time horizon. So after this observation many researchers worked on the inventory models for deteriorating items. Moon et al. (2005) developed an economic order quantity models for ameliorating/deteriorating items under inflation and time discounting. Yang et al. (2010) introduced an inventory model under inflation for deteriorating items with stock-dependent consumption rate and partial backlogging of occurring shortages. Chang et al. (2010) developed an inventory model with stock and price dependent demand rate for deteriorating items based on limited shelf space. Goyal et al. (2013) presented an EPQ model with stock dependent demand and time varying deterioration with shortages under inflationary environment. Tayal et al. (2014) presented a multi item inventory model for deteriorating items with expiration date and allowable shortages.

Singh et al. (2014) presented an analysis of three level supply chain of inventory with deterioration for multi items. Tayal et al. (2014) also introduced an inventory model for deteriorating item with space constraints. Singh and Rathore (2014) developed an inventory model for deteriorating item with reliability consideration and trade credit. Jaggi et al. (2015) come forward with two-warehouse inventory model for deteriorating items with price sensitive demand and partially backlogged shortages under inflationary environment conditions. After that Tayal et al. (2015) presented a production inventory framework for non-instantaneous deteriorating items with time dependent holding cost and exponential demand rate. Since there are so many products which maintain their quality for a fix period of time and after that it begins to deteriorate. In the development of inventory models it was assumed that deterioration of the products is non-controllable, but preservation is that technique from which the deterioration can be controlled up to a certain limit. Tayal et al. (2014) presented an inventory policy for deteriorating inventory in which preservation technology was used for the reduction of existing rate of deterioration. An inventory model for deteriorating items with seasonal products and an option of an alternative market was presented by Tayal et al. (2014). In this paper, to prevent the cost of deterioration and holding stock, after some time, the remaining stock is transferred to an alternative market.

Traditionally, in inventory modeling, it was assumed that the retailer has to pay the supplier instantly, at the time, he/she receives the stock. But generally, the supplier considers a certain time period to the retailer to pay all the dues. During this credit period the retailer may begin to accumulate revenues on the sales and earn interest on that revenue, but beyond this period, the supplier charges interest on unpaid balance. Thus, this time period allowed by the supplier to the retailer, works as a promotional tool to encourage the business. Kumar and Singh (2009) introduced a two warehouse inventory model with stock dependent demand for deteriorating items with shortages. Singh and Sharma (2014) developed an optimal trade-credit policy for perishable items deeming imperfect production and stock dependent demand. Tayal et al. (2015) also introduced an integrated production inventory model for perishable products with trade credit period and investment in preservation technology. Shastri et al. (2014) presented a supply chain management for two level trade credit financing with selling price dependent demand under the effect of preservation technology.

Further, in most of all developed models in inventory, the primary assumption is that during stock out the occurring shortages are either completely lost or completely backlogged, but this is not realistic. During stock-out some customers may go to others to make their purchases and some other customers come back at the arrival of stock, which term is known as partial backlogging. Bhunia and Maiti (1997) 
developed a deterministic inventory replenishment problem for deteriorating items with time dependent demand and shortages for the finite time horizon.

Chern et al. (2008) presented partial backlogging inventory lot-size models for deteriorating items with fluctuating demand under inflation. Shukla et al. (2013) introduced an inventory model for deteriorating items with exponential demand rate and shortages. Kumar et al. (2013) presented a learning effect on an inventory model with two level storage and partial backlogging under inflation. Models of inventory management contain different parameters. An issue is observable in the classical models which can be associated with the determination of the quantity of the economic order and the quantity of the economic production. In these models, the ordering cost is treated as a constant cost per order. This matter causes the quantity of the economic ordering in the classic model to have some differences in comparison with the real-world conditions. Pattnaik (2013) presented an instantaneous economic order quantity (EOQ) model for deteriorating items incorporated with promotional effort cost, variable ordering cost.

In the present study, we tried to merge all above mentioned factors into a single problem. The whole environment of business dealings has been assumed, which conforms to the practical market situations. The supplier allows a permissible delay period to the retailer to pay all the dues. Considering the real life situations ordering cost is also taken as time dependent. Here the retailer invests on preservation expenses, to reduce the rate of deterioration. However, there is a constraint up to which deterioration rate can be reduced; hence an upper bound is also involved.

\section{Assumptions and Notations}

\section{Assumptions}

The following assumptions are used in the development of this model.

1. The demand for the product follows a function of available stock at that time and is given by: $\mathrm{D}(\mathrm{t})=$ $\left(\mathrm{a}+\mathrm{bI}_{\mathrm{b} 1}(\mathrm{t})\right)$

2. Due to impatient customers the demand during stock out is partially lost.

3. The backlogged demand is satisfied first at the arrival of next lot.

4. The products are deteriorating in nature.

5. There is no replacement of deteriorated items.

6. A preservation technology cost is applied to reduce the existing rate of deterioration.

7. The supplier allows a permissible delay period $\mathrm{M}$ to the retailer to settle the account during which the supplier does not charge any interest.

8. The ordering cost is treated as an increasing function of time.

8. The reduced deterioration rate is a function of the preservation technology cost $\zeta$ such that, $m(\zeta)=K\left(1-e^{-x \zeta}\right), \mathrm{u} \geq 0$,

where $\mathrm{x}$ is a coefficient representing the percentage increase in $\mathrm{m}(\zeta)$ per dollar increase in $\zeta$ which shows that $m(\zeta)$ is an increasing function bounded above by $\mathrm{K}$.

\section{Notations}

These are the notations used throughout this chapter.

$p \quad$ selling price per unit

$K \quad$ constant rate of deterioration

$a$ initial demand rate

$b \quad$ positive demand coefficient

c purchasing cost per unit 
$M \quad$ allowed credit period to the retailer by the supplier to settle the account

$I_{e} \quad$ rate of interest earned by the retailer

$I_{c} \quad$ rate of interest charged by the retailer after $\mathrm{M}$, on unpaid amount

$Q \quad$ initial inventory level

$h \quad$ holding cost per unit per unit

$s \quad$ shortage cost per unit

$l \quad$ lost sale cost per unit

$d \quad$ deterioration cost per unit

$c_{o} \quad$ ordering cost per unit

$\theta \quad$ positive constant, $0<\theta \leq 1$

$t_{1} \quad$ time at which inventory level becomes zero

$T$ replenishment cycle for the retailer

$m(\zeta)$ a function representing the reduced deterioration rate

$\zeta \quad$ preservation technology cost

$n \quad$ number of replenishment cycles

\section{Mathematical Model}

In this section, we have developed a mathematical inventory model for the products having stock dependent demand. The inventory system during a given cycle is depicted in Fig. 1. The inventory cycle starts at $t=0$ with an initial stock of $Q$ units of items. From $t=0$ to $t=t_{1}$, the inventory depletes due to combined effect of demand and deterioration. After this the shortages occurs and the occurring demand during shortages are partially backlogged and this process is goes on.

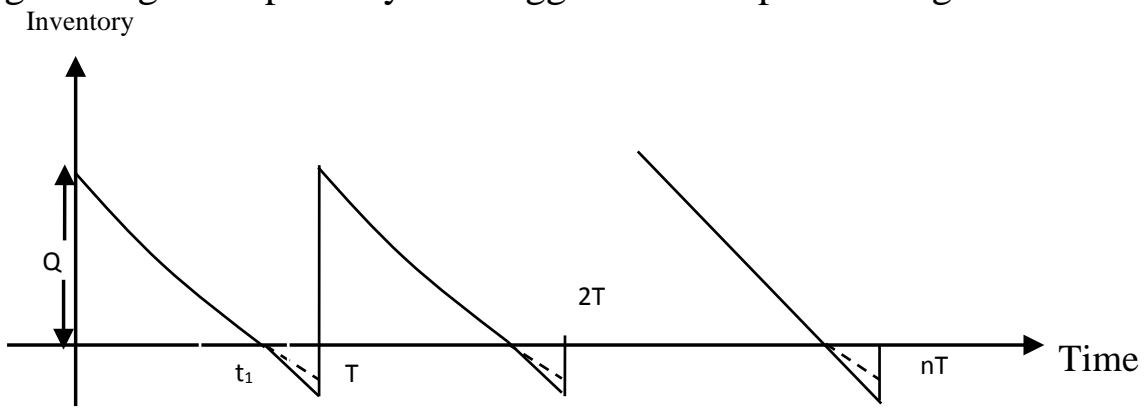

Fig. 1. Inventory time graph for retailer

$$
\begin{array}{ll}
\frac{d I_{b 1}(t)}{d t}+(K-m(\zeta)) I_{b 1}(t)=-\left(a+b I_{b 1}(t)\right) & 0 \leq t \leq t_{1} \\
\frac{d I_{b 2}(t)}{d t}=-\theta a & t_{1} \leq t \leq T
\end{array}
$$

with boundary conditions:

$$
I_{b 1}(0)=Q, \quad I_{b 1}\left(t_{1}\right)=0
$$

The solutions of these equations are given by:

$$
\begin{array}{lrl}
I_{b 1}(t) & =\frac{a}{(b+K-m(\zeta))}\left(e^{(b+K-m(\zeta))\left(t_{1}-t\right)}-1\right) & 0 \leq t \leq t_{1} \\
I_{b 2}(t) & =\theta a\left(t_{1}-t\right) & t_{1} \leq t \leq T
\end{array}
$$

\section{Cost Analysis}

(i) Holding Cost:

H.C. $=\frac{h}{T} \int_{0}^{t_{1}} I_{b 1}(t) d t$ 
H.C. $=\frac{h}{T}\left\{\frac{a}{b}(b+K-m(\zeta))\right\} \frac{t_{1}^{2}}{2}$

(ii) Deterioration Cost:

D.C. $=\frac{d}{T}\left(I_{1}(0)-\right.$ total demand $)$

D.C. $=\frac{d}{T}\left[\frac{a}{b}\left(e^{(b+K-m)}-1\right)-\left\{a t_{1}+b a \frac{t_{1}^{2}}{2}\right\}\right]$

(iii) Ordering Cost:

$$
\begin{aligned}
& \text { O. } C_{b}=\frac{1}{T}\left[\int_{0}^{t_{1}}\left(c_{o}+\beta_{2} t\right) d t+\int_{t_{1}}^{T}\left(c_{o}+\beta_{2} t\right) d t\right] \\
& \text { O. } C_{b}=\frac{1}{T}\left[c_{o} T+\beta_{2} \frac{T^{2}}{2}\right]
\end{aligned}
$$

(iv) Shortage Cost:

$$
\begin{aligned}
& S . C_{b}=\frac{S}{T} \int_{t_{1}}^{T} \theta a d t \\
& S . C_{b}=\frac{S}{T} \theta a\left(T-t_{1}\right)
\end{aligned}
$$

(v) Lost Sale Cost:

$$
\begin{aligned}
& \text { L.S.C } C_{b}=\frac{l}{T} \int_{t_{1}}^{T}(1-\theta) a d t \\
& \text { L.S.C } C_{b}=\frac{l}{T}(1-\theta) a\left(T-t_{1}\right)
\end{aligned}
$$

Now based on the permissible delay period allowed to retailer two cases arises:

\section{Case 1: $M \geq t_{1}$}

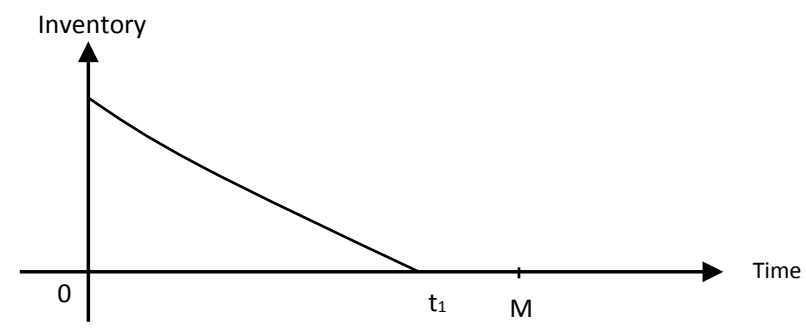

Case 2: $M<t_{1}$

Fig. 2. When $M \geq t_{1}$

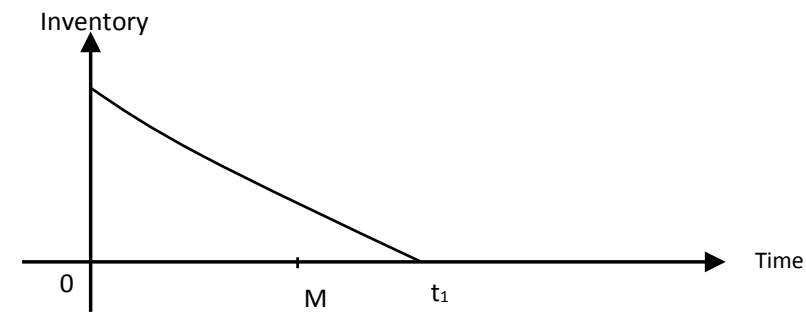

Fig. 3. When $\mathrm{M}<\mathrm{t}_{1}$ 
(vi) Interest Earned:

Case 1: When $M \geq t_{1}$

In this case, the retailer deposits all the income in an interest bearing account,

$$
\begin{aligned}
& I E_{1}=p \frac{I_{e}}{T}\left[\int_{0}^{t_{1}}\left(a+b I_{b}(t)\right) t d t+\left(M-t_{1}\right) \int_{0}^{t_{1}}\left(a+b I_{b}(t)\right) d t\right] \\
& I E_{1}=p \frac{I_{e}}{T}\left[\left\{\frac{a t_{1}^{2}}{2}-\frac{b a}{(b+K-m(\zeta))}\left(\left(\frac{t_{1}}{(b+K-m(\zeta))}+\frac{1}{(b+K-m(\zeta))^{2}}\right)-\frac{t_{1}^{2}}{2}\right)+\frac{b a e^{(b+K-m(\zeta)) t_{1}}}{(b+K-m(\zeta))^{3}}\right\}\right. \\
&\left.+\left(M-t_{1}\right)\left\{a t_{1}-\frac{b a}{b+K-m(\zeta)}\left(\frac{1}{(b+K-m(\zeta))}+t_{1}\right)+\frac{b a}{(b+K-m(\zeta))^{2}} e^{(b+K-m(\zeta)) t_{1}}\right\}\right]
\end{aligned}
$$

Case 2: When $M<t_{1}$

In this case interest earned during $[0, \mathrm{M}]$ is as follows,

$$
\begin{aligned}
I E_{2}= & \frac{p I_{e}}{T} \int_{0}^{M}\left(a+b I_{b 1}(t)\right) t d t \\
I E_{2}= & \frac{p I_{e}}{T}\left[\frac{a M^{2}}{2}-\frac{b a}{(b+K-m(\zeta))}\left\{M\left(\frac{e^{(b+K-m(\zeta))\left(t_{1}-M\right)}}{(b+K-m(\zeta))}+M\right)+\frac{1}{(b+K-m(\zeta))^{2}} e^{(b+K-m(\zeta))\left(t_{1}-M\right)}\right.\right. \\
& \left.\left.-\frac{M^{2}}{2}\right\}+\frac{b a}{(b+K-m(\zeta))^{3}} e^{(b+K-m(\zeta)) t_{1}}\right]
\end{aligned}
$$

(vii) Interest Charged

The retailer purchases the items at a rate of c Rs/unit and sells them at a selling price of $\mathrm{p}$ Rs/unit.

During $[0, \mathrm{M}]$ the total sales amount $=\int_{0}^{M} D(0, M) d t$

Now based on the available total capital to the retailer at time $\mathrm{t}=\mathrm{M}$, two different cases arises:

(2.1) When $p D(0, M)+I E_{2} \geq c Q$

(2.2) When $p D(0, M)+I E_{2}<c Q$

Case 1: When $M \geq t_{1}$ :

In this case the retailer has enough money to pay all dues to the vendor at $\mathrm{t}=\mathrm{M}$, so:

$\mathrm{IC}_{1}=0$

Case 2: When $M<t_{1}$ :

In this case we will discuss the both above mentioned conditions based on the available total capital to the retailer as follows,

(2.1) When $p D(0, M)+I E_{2} \geq c Q$

In this case the total available capital to the retailer is enough to pay to the vendor at $\mathrm{t}=\mathrm{M}$, So $\mathrm{I}$. $\mathrm{C}_{2.1}=0$

(2.2) When $p D(0, M)+I E_{2}<c Q$ 
In this case the retailer has not enough money. So he has to pay interest on unpaid balance.

Unpaid balance $\left(\mathrm{U}_{1}\right)=\mathrm{cQ}-\left(\mathrm{pD}(0, \mathrm{M})+\mathrm{I} . \mathrm{E}_{2}\right)$

$$
\begin{aligned}
& p D(0, M)=p \int_{0}^{M}\{a+b I(t)\} d t \\
& p D(0, M)=p\left[a M-\frac{b a}{(b+K-m(\zeta))}\left(\frac{e^{(b+K-m(\zeta))\left(t_{1}-M\right)}}{(b+K-m(\zeta))}+M\right)+\frac{b a}{(b+K-m(\zeta))^{2}} e^{(b+K-m(\zeta)) t_{1}}\right]
\end{aligned}
$$

So the interest charged in this case will be:

$$
\text { I. } C_{2.2}=\frac{U_{1}}{T}\left(t_{1}-M\right) I c
$$

(viii) Total Cost for the Retailer:

Case 1: When $M \geq t_{1}$ :

T.A.C ${ }_{1}=$ H.Cb + O.Cb + D.C $C_{b}+$ S.C $C_{b}+$ L.S.C $C_{b}+$ P.T.C $C_{b}+$ I.C $_{1}-$ I.E $_{1}$

Case 2: When $M<t_{1}$ :

(2.1) When $p D(0, M)+I E_{2} \geq c Q$

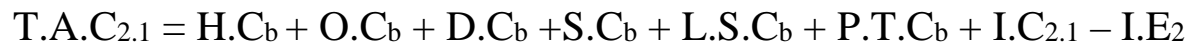

(2.2) When $p D(0, M)+I E_{2}<c Q$

T.A.C $2.2=$ H.C $C_{b}+$ O.C $C_{b}+$ D. $C_{b}+$ S.C $b+$ L.S.Cb + P.T.C $C_{b}+$ I.C $2.2-$ I.E2

\section{Numerical Analysis}

The model can be illustrated by the given numerical example for which the system parameters are as follows.

Case 1: When $M \geq t_{1}$ :

$\mathrm{a}=200$ units, $\mathrm{b}=0.05, \mathrm{x}=0.01, \mathrm{~K}=0.01, \mathrm{~h}=0.5 \mathrm{Rs} /$ unit, $\mathrm{d}=4 \mathrm{Rs} /$ unit, $\mathrm{M}=45$ days, $\mathrm{l}=8 \mathrm{Rs} / \mathrm{unit}$, $\theta=0.7, \mathrm{~s}=6 \mathrm{Rs} /$ unit, $\mathrm{T}=50$ days, $\mathrm{Ie}=0.01 \%, \mathrm{p}=30 \mathrm{Rs} / \mathrm{unit}, \beta_{1}=0.02, \beta_{2}=0.025$

For these values the optimal value of preservation technology cost $(\xi)$ and critical point $\left(\mathrm{t}_{1}\right)$ comes out to be Rs. 35.5791 and 29.7055 days respectively and corresponding to these the minimum total average cost is Rs. 49.4747.

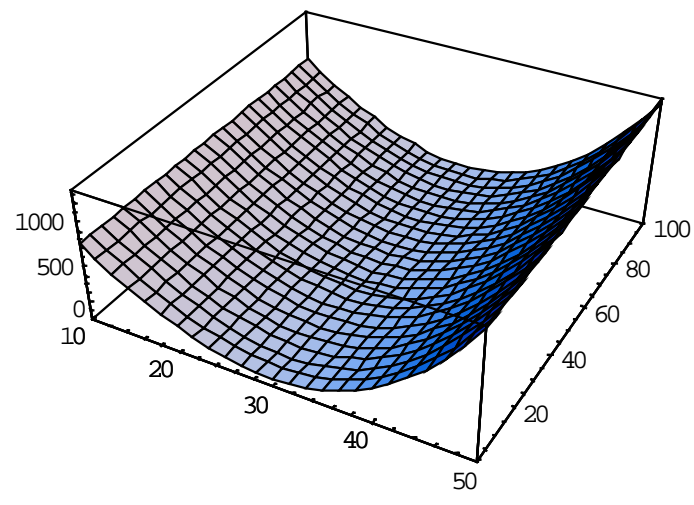

Fig. 4. Behavior of the T.A.C. function when $M \geq t_{1}$

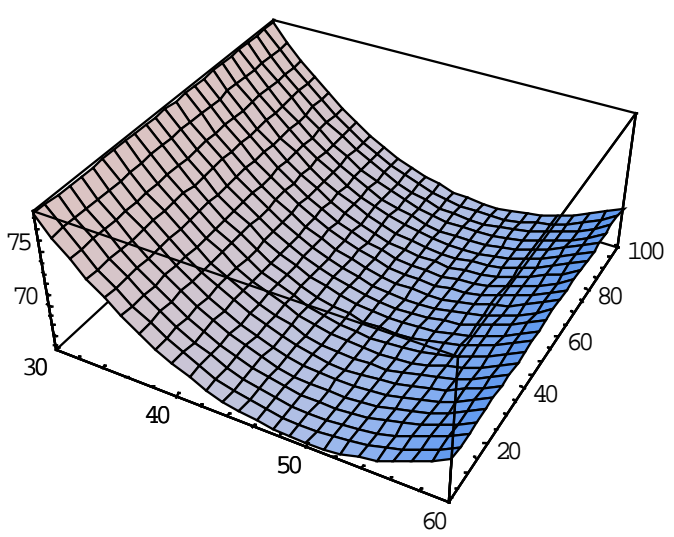

Fig. 5. Behavior of the T.A.C. function when $\mathrm{M}<\mathrm{t}_{1}$ 
Case 2: When $M<t_{1}$ :

Here we will discuss only the subcase (2.1) when $\mathrm{pD}(0, \mathrm{M})+\mathrm{I}_{2} \mathrm{E}_{2}<\mathrm{cQ}$ :

$\mathrm{a}=200$ units, $\mathrm{b}=0.05, \mathrm{x}=0.01, \mathrm{~K}=0.01, \mathrm{~h}=0.5 \mathrm{Rs} / \mathrm{unit}, \mathrm{d}=4 \mathrm{Rs} / \mathrm{unit}, \mathrm{M}=45$ days, $\mathrm{l}=8 \mathrm{Rs} / \mathrm{unit}$, $\theta=0.7, \mathrm{~s}=6$ Rs/unit, $\mathrm{T}=50$ days, $\mathrm{I}_{\mathrm{e}}=0.01 \%, \mathrm{I}_{\mathrm{c}}=0.02 \%, \mathrm{p}=30 \mathrm{Rs} /$ unit, $\beta_{1}=0.02, \beta_{2}=0.025$

For these values the optimal value of preservation technology cost $(\xi)$ and critical point $\left(\mathrm{t}_{1}\right)$ comes out to be Rs. 40.8838 and 49.4342 days respectively and corresponding to these the minimum total average cost is Rs. 40.8838.

\section{Sensitivity Analysis}

Sensitivity analysis is carried out with respect to different system parameters.

Case 1: When $M \geq t_{1}$

Table 1

Sensitivity analysis with respect to demand parameter $a$

\begin{tabular}{cccc}
\hline$\%$ variation in a & $\xi$ & $\mathrm{t}_{1}$ & T.A.C. \\
\hline$-20 \%$ & 35.5683 & 29.6968 & 97.3625 \\
$-15 \%$ & 35.5715 & 29.6993 & 85.391 \\
$-10 \%$ & 35.5743 & 29.7016 & 73.4192 \\
$-5 \%$ & 35.5769 & 29.7036 & 61.447 \\
$0 \%$ & 35.5791 & 29.7055 & 49.4747 \\
$5 \%$ & 35.5812 & 29.7071 & 37.5019 \\
$10 \%$ & 35.583 & 29.7086 & 25.5292 \\
$15 \%$ & 35.5847 & 29.71 & 13.5562 \\
20 & 35.5863 & 29.7113 & 1.58296 \\
\hline
\end{tabular}

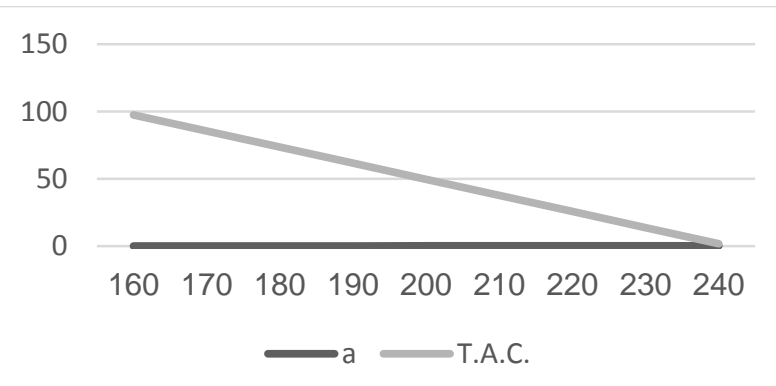

Fig. 6. T.A.C. v/s a

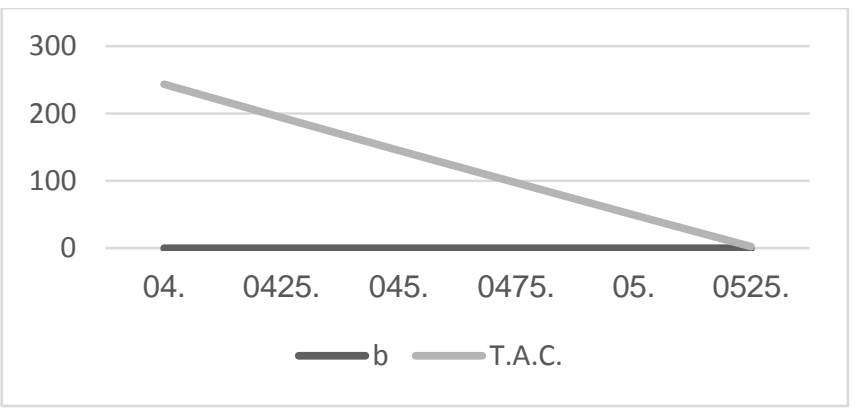

Fig. 7. T.A.C. v/s b

Table 2

Sensitivity analysis with respect to demand parameter $b$

\begin{tabular}{cccc}
\hline \% variation in b & $\xi$ & $\mathrm{t}_{1}$ & T.A.C. \\
\hline$-20 \%$ & 33.6306 & 28.1334 & 243.431 \\
$-15 \%$ & 34.1794 & 28.5762 & 193.924 \\
$-10 \%$ & 34.6836 & 28.983 & 145.176 \\
$-5 \%$ & 35.1487 & 29.3582 & 97.0605 \\
$0 \%$ & 35.579 & 29.7055 & 49.4748 \\
$5 \%$ & 35.9788 & 30.0279 & 2.33597 \\
$10 \%$ & 36.351 & 30.3282 & - \\
$15 \%$ & 36.6985 & 30.6086 & - \\
$2 \%$ & 37.0237 & 30.871 & - \\
\hline
\end{tabular}


Table 3

Sensitivity analysis with respect to coefficient $x$

\begin{tabular}{cccc}
\hline$\%$ variationin $\mathrm{x}$ & $\xi$ & $\mathrm{t}_{1}$ & T.A.C. \\
\hline$-20 \%$ & 35.3219 & 29.498 & 68.9841 \\
$-15 \%$ & 35.3858 & 29.5495 & 64.1546 \\
$-10 \%$ & 35.4499 & 29.6012 & 59.2935 \\
$-5 \%$ & 35.5144 & 29.6532 & 54.4002 \\
$0 \%$ & 35.5791 & 29.7055 & 49.4747 \\
$5 \%$ & 35.6442 & 29.758 & 44.5163 \\
$10 \%$ & 35.7095 & 29.8107 & 39.525 \\
$15 \%$ & 35.7752 & 29.8637 & 34.5002 \\
20 & 35.8412 & 29.9169 & 29.4418 \\
\hline
\end{tabular}

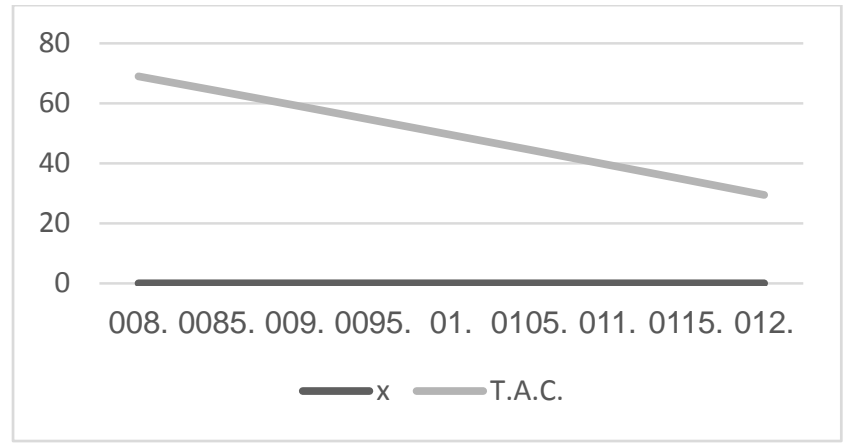

Fig. 8. T.A.C. $v / s x$

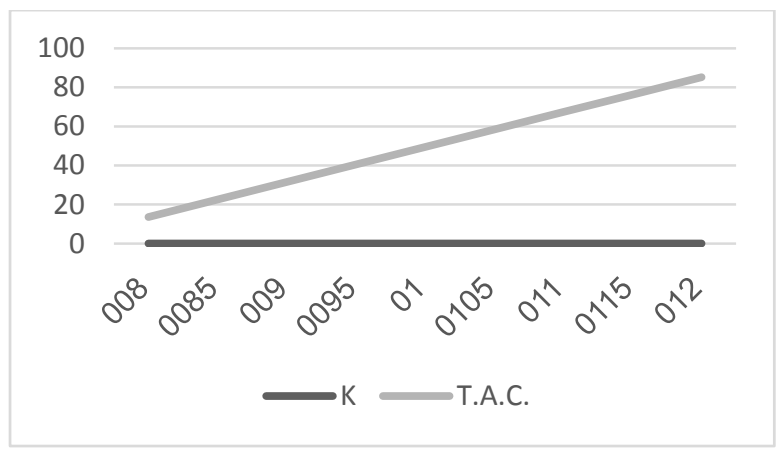

Fig. 9. T.A.C. v/s K

\section{Table 4}

Sensitivity analysis with respect to demand parameter deterioration rate $K$

\begin{tabular}{cccc}
\hline \% variation in $\mathrm{K}$ & $\xi$ & $\mathrm{t}_{1}$ & T.A.C. \\
\hline$-20 \%$ & 36.0475 & 30.0834 & 13.5611 \\
$-15 \%$ & 35.9307 & 29.9892 & 31.562 \\
$-10 \%$ & 35.8137 & 29.8948 & 40.519 \\
$-5 \%$ & 35.6965 & 29.8002 & 49.4747 \\
$0 \%$ & 35.5791 & 29.7055 & 58.4149 \\
$5 \%$ & 35.4615 & 29.6106 & 67.3394 \\
$10 \%$ & 35.3437 & 29.5155 & 76.2482 \\
$15 \%$ & 35.2256 & 29.4203 & 85.1406 \\
\hline
\end{tabular}

\section{Table 5}

Sensitivity analysis with respect to backlogging rate $\theta$

\begin{tabular}{cccc}
\hline$\%$ variation in $\theta$ & $\xi$ & $\mathrm{t}_{1}$ & T.A.C. \\
\hline$-20 \%$ & 35.8491 & 29.9233 & 71.6148 \\
$-15 \%$ & 35.7818 & 29.869 & 66.1031 \\
$-10 \%$ & 35.7143 & 29.8146 & 60.576 \\
$-5 \%$ & 35.6468 & 29.7601 & 55.0331 \\
$0 \%$ & 35.5791 & 29.7055 & 49.4747 \\
$5 \%$ & 35.5113 & 29.6508 & 43.9006 \\
$10 \%$ & 35.4434 & 29.596 & 38.3107 \\
$15 \%$ & 35.3754 & 29.5411 & 32.7052 \\
$2 \%$ & 35.3072 & 29.4861 & 27.084 \\
\hline
\end{tabular}




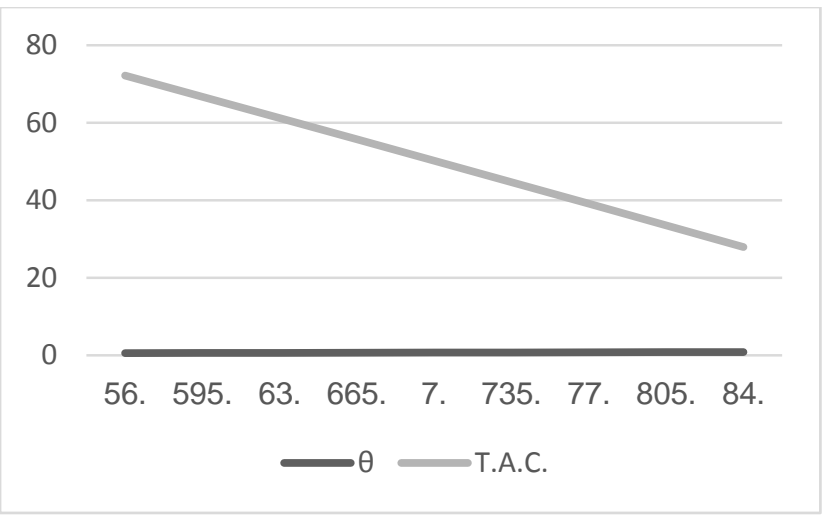

Fig. 10. T.A.C. v/s $\theta$

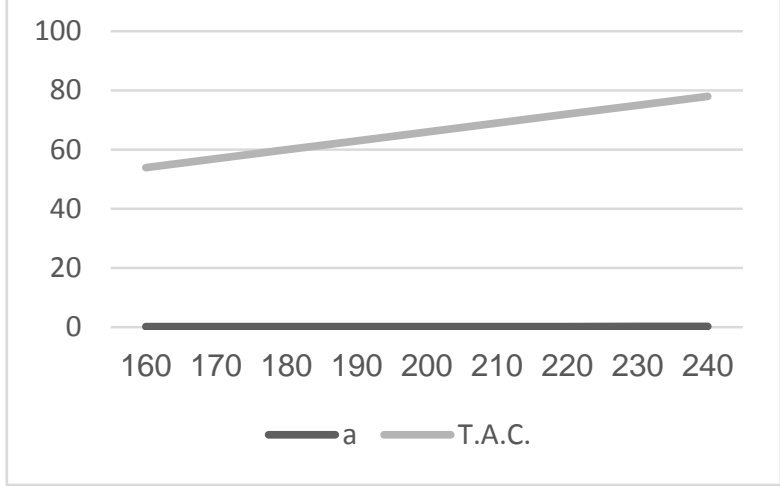

Fig. 11. T.A.C. v/s a

Case 2: When $\mathrm{M}<\mathrm{t}_{1}$ :

Table 6

Sensitivity analysis with respect to demand parameter $a$

\begin{tabular}{cccc}
\hline \% variation in a & $\xi$ & $\mathrm{t}_{1}$ & T.A.C. \\
\hline$-20 \%$ & 40.8838 & 49.4342 & 53.7819 \\
$-15 \%$ & 40.8838 & 49.4342 & 56.7789 \\
$-10 \%$ & 40.8838 & 49.4342 & 59.7759 \\
$-5 \%$ & 40.8838 & 49.4342 & 62.7729 \\
$0 \%$ & 40.8838 & 49.4342 & 65.7699 \\
$5 \%$ & 40.8838 & 49.4342 & 68.7669 \\
$10 \%$ & 40.8838 & 49.4342 & 71.7638 \\
$15 \%$ & 40.8838 & 49.4342 & 74.7608 \\
$20 \%$ & 40.8838 & 49.4342 & 77.7578 \\
\hline
\end{tabular}

Table 7

Sensitivity analysis with respect to demand parameter $b$

\begin{tabular}{cccc}
\hline$\%$ variation in b & $\xi$ & $\mathrm{t}_{1}$ & T.A.C. \\
\hline$-20 \%$ & 40.1549 & 48.5307 & 63.1351 \\
$-15 \%$ & 40.2984 & 48.7086 & 64.1276 \\
$-10 \%$ & 40.4682 & 48.919 & 64.8729 \\
$-5 \%$ & 40.6635 & 49.1611 & 65.4099 \\
$0 \%$ & 40.8838 & 49.4342 & 65.7699 \\
$5 \%$ & 41.1285 & 49.7374 & 65.9776 \\
$10 \%$ & 41.3969 & 50.0702 & 66.053 \\
$15 \%$ & 41.6888 & 50.432 & 66.0124 \\
$20 \%$ & 42.0038 & 50.8223 & 65.8688 \\
\hline
\end{tabular}

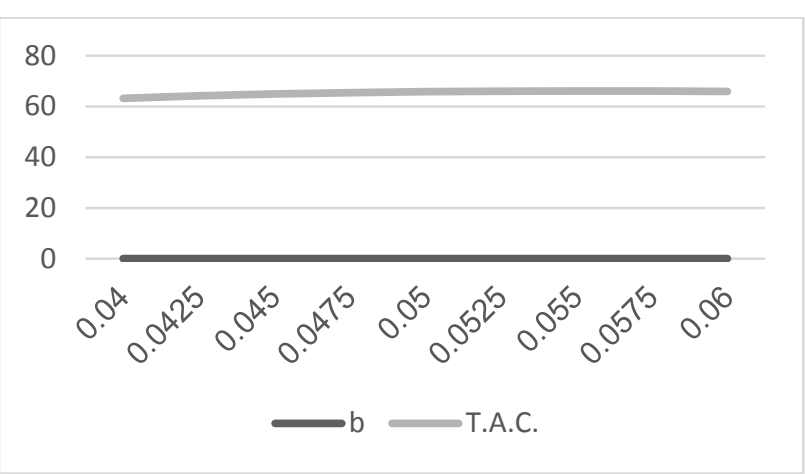

Fig. 12. T.A.C. v/s b

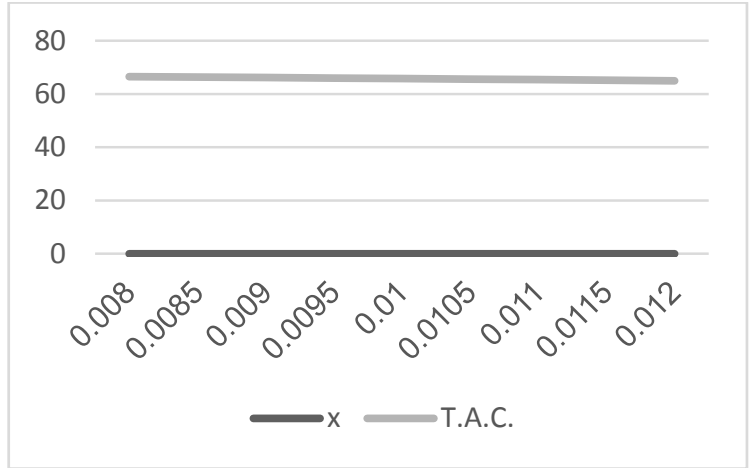

Fig. 13. T.A.C. v/s $x$ 
Table 8

Sensitivity analysis with respect to coefficient $x$

\begin{tabular}{cccc}
\hline \% variation in $\mathrm{x}$ & $\xi$ & $\mathrm{t} 1$ & T.A.C. \\
\hline$-20 \%$ & 40.3017 & 48.7126 & 66.5225 \\
$-15 \%$ & 40.4437 & 48.8887 & 66.3406 \\
$-10 \%$ & 40.588 & 49.0675 & 66.1547 \\
$-5 \%$ & 40.7347 & 49.2494 & 65.9645 \\
$0 \%$ & 40.8838 & 49.4342 & 65.7699 \\
$5 \%$ & 41.0354 & 49.6221 & 65.5708 \\
$10 \%$ & 41.1897 & 49.8133 & 65.3668 \\
$15 \%$ & 41.3466 & 50.0078 & 65.1579 \\
20 & 41.5063 & 50.2058 & 64.9439 \\
\hline
\end{tabular}

\section{Table 9}

Sensitivity analysis with respect to deterioration rate $K$

\begin{tabular}{cccc}
\hline \% variation in $\mathrm{K}$ & $\xi$ & $\mathrm{t}_{1}$ & T.A.C. \\
\hline$-20 \%$ & 41.7642 & 50.5254 & 64.5952 \\
$-15 \%$ & 41.5421 & 50.2501 & 64.8957 \\
$-10 \%$ & 41.3213 & 49.9765 & 65.1917 \\
$-5 \%$ & 41.1019 & 49.7045 & 65.483 \\
$0 \%$ & 40.8838 & 49.4342 & 65.7699 \\
$5 \%$ & 40.6671 & 49.1655 & 66.0523 \\
$10 \%$ & 40.4517 & 48.8986 & 66.3304 \\
$15 \%$ & 40.2377 & 48.6333 & 66.6041 \\
20 & 40.025 & 48.3697 & 66.066 \\
\hline
\end{tabular}

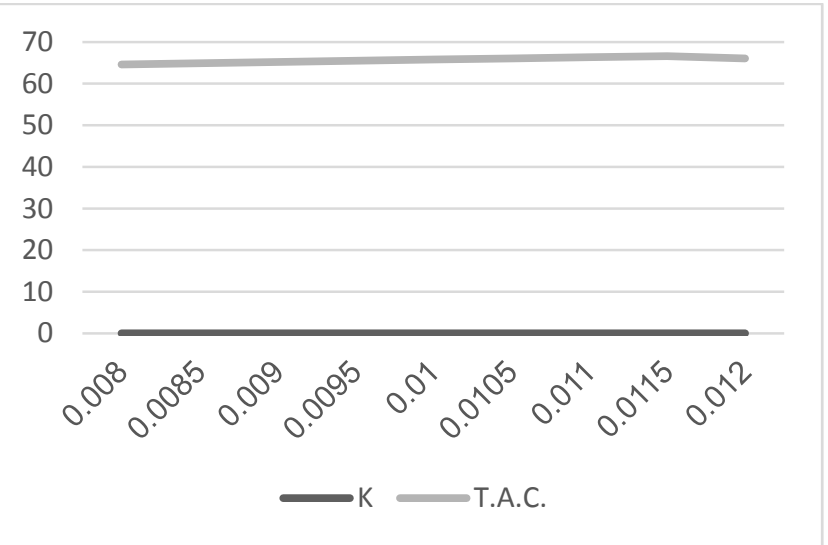

Fig. 14. T.A.C. v/s K

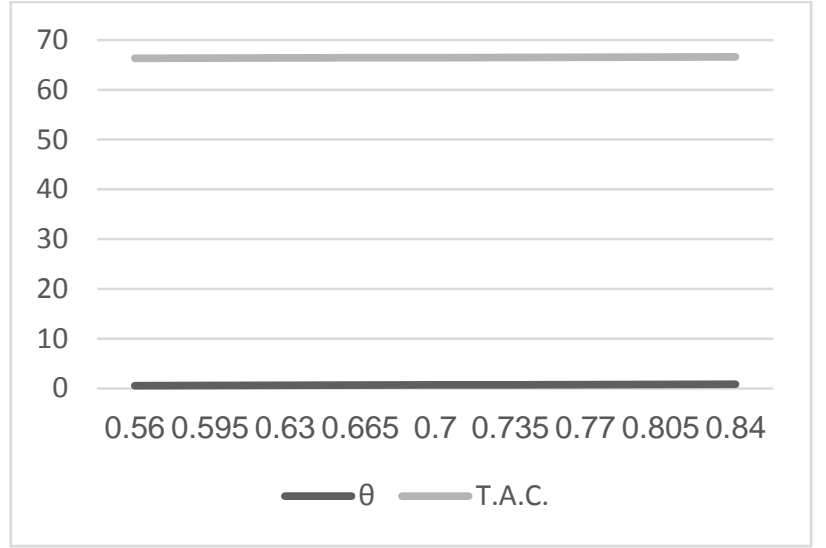

Fig.15. T.A.C. v/s $\theta$

Table 10

Sensitivity analysis with respect to backlogging rate $\theta$

\begin{tabular}{cccc}
\hline$\%$ variation in $\theta$ & $\xi$ & $\mathrm{t}_{1}$ & T.A.C. \\
\hline$-20 \%$ & 41.1763 & 49.7967 & 65.7574 \\
$-15 \%$ & 41.1032 & 49.7061 & 65.7613 \\
$-10 \%$ & 41.03 & 49.6154 & 65.7647 \\
$-5 \%$ & 40.9569 & 49.5248 & 65.7676 \\
$0 \%$ & 40.8838 & 49.4342 & 65.7699 \\
$5 \%$ & 40.8107 & 49.3436 & 65.7716 \\
$10 \%$ & 40.7376 & 49.253 & 65.7728 \\
$15 \%$ & 40.6646 & 49.1625 & 65.7735 \\
20 & 40.5915 & 49.0719 & 65.7736 \\
\hline
\end{tabular}




\subsection{Observations}

1. From Table 1 we observe that with the increment in demand parameter (a) T.A.C. decreases.

2. In Table 6, with the increment in demand parameter (a), T.A.C. increases for the second case of allowable credit period.

3. Table 2 and Table 7 show the variation in demand parameter (b) and other variables unchanged; from Table 2 we observe that as the value of $b$ increases T.A.C. decreases, and from Table 6 it is observed that with the increment in $b$, T.A.C. increases up to a fix point and after that it begins to decrease.

4. Table 3 and Table 8 represent the variation in coefficient $x$, in this as the value of $x$ increases, T.A.C. also increases.

5. Table 4 and Table 9 show the variation in deterioration rate $K$ in different cases, it is observed that with the increment in deterioration rate $K$, T.A.C. of the system increases in both the cases.

6. From Table 5 and Table 10, we observe the behavior of T.A.C. with the increment in backlogging rate $(\theta)$, as the value of backlogging rate increases T.A.C. decreases in first case and shows the reverse effect in second case.

\section{Conclusion}

In this paper we have studied an inventory model, in which demand is stock dependent, and the supplier allows a certain period to the retailer to pay all the dues, during which no interest is charged. Different cases of allowable credit period are discussed. The main contribution of this paper has been the development of a dynamic heuristic to determine the optimal preservation cost, shortage period and optimal total cost under the environment of trade credit and variable ordering cost in which the products are deteriorating in nature and demand is stock dependent. In totality, the setup that has been chosen boasts of uniqueness in terms of the conditions under which the model has been developed.

A numerical assessment of the theoretical model has been done to illustrate the theory. The solution obtained has also been checked for sensitivity. The model developed here may further be extended for more conditions of permissible delay, demand, deterioration and time value of money.

\section{Acknowledgement}

The authors wish to express gratitude the reviewers for their cooperative and valuable suggestions.

\section{References}

Bhunia, A.K., Maiti, M. (1997). A deterministic inventory replenishment problem for deteriorating items with time dependent demand and shortages for the finite time horizon, OPSEARCH, 34(1), 51-61.

Chang, C.T., Chen, Y.J., Tsai, T.R., \& Wu, S.J. (2010). Inventory models with stock and price dependent demand rate for deteriorating items based on limited shelf space. Yugoslav Journal of Operation Research, 21(1), 55-69.

Chern, M. S., Yang, H. L., Teng, J. T., \& Papachristos, S. (2008). Partial backlogging inventory lotsize models for deteriorating items with fluctuating demand under inflation. European Journal of Operational Research, 191(1), 127-141. 
Goyal, A., Singh, S. R., \& Chauhan, A. (2013). An EPQ model with stock dependent demand and time varying deterioration with shortages under inflationary environment, International Journal of Agricultural and Statistical Sciences, 9(1), 173-182.

Jaggi, C.K., Pareek, S., Khanna, A., \& Sharma, R. (2015). Two-warehouse inventory model for deteriorating items with price sensitive demand and partially backlogged shortages under inflationary environment conditions. International Journal of Industrial Engineering Computation, 6(1), 59-80.

Kumar, N., \& Singh S. R. (2009). Two warehouse inventory model with stock dependent demand for deteriorating items with shortages, The IUP Journal of Computational Mathematics, 2(3), 7-23.

Kumar, N., Singh, S. R., \& Kumari, R. (2013). Learning effect on an inventory model with twolevel storage and partial backlogging under inflation, International Journal of Services and Operations Management, 16(1), 105-122.

Moon, I., Giri, B.C., \& Ko, B. (2005). Economic order quantity models for ameliorating/deteriorating items under inflation and time discounting. European Journal of Operational Research, 162(3), 773-785.

Pattnaik, M. (2013). Optimization in an instantaneous economic order quantity (EOQ) model incorporated with promotional effort cost, variable ordering cost and units lost due to deterioration. Uncertain Supply Chain Management, 1(4), 57-66.

Shastri, A., Singh, S. R., Yadav, D., \& Gupta S. (2014), Supply chain management for two level trade credit financing with selling price dependent demand under the effect of preservation technology, International Journal of Procurement Management, 7(6), 695-718.

Shukla, H. S., Shukla, V., \& Yadav, S. K. (2013). EOQ model for deteriorating items with exponential demand rate and shortages. Uncertain Supply Chain Management, 1(2), 67-76.

Singh, C., \& Singh, S. R. (2012). An EPQ model with power form stock dependent demand under inflationary environment using genetic algorithm. International Journal of Computer Applications, 48(15), 25-30.

Singh, N., Vaish, B., \& Singh S. R. (2014). Analysis of three level supply chain of inventory with deterioration for multi items. International Journal of Industrial Engineering Computations, 5(3), 417-430.

Singh, S. R., \& Rathore, H. (2014). An inventory model for deteriorating item with reliability consideration and trade credit. Pakistan Journal of Statistics and Operation Research, 10(3), 349360.

Singh, S. R., \& Sharma, S. (2014). Optimal trade-credit policy for perishable items deeming imperfect production and stock dependent demand. International Journal of Industrial Engineering Computations, 5(1), 151-168.

Singh, S. R., \& Singh, C. (2008). Optimal ordering policy for decaying items with stock-dependent demand under inflation in a supply chain. International Review of Pure and Applied Mathematics, 3(2), 189-197.

Singh, S. R., Kumari, R., \& Kumar, N. (2010). Replenishment policy for non-instantaneous deteriorating items with stock-dependent demand and partial back logging with two-storage facility under inflation. International Journal of Operations Research and Optimization, 1 (1), 161-179.

Singhal, S., \& Singh, S. R. (2015). Modeling of an inventory system with multi variate demand under volume flexibility and learning. Uncertain Supply Chain Management, 3(2), 147-158.

Tayal, S., Singh, S. R., \& Sharma, R. (2014). A multi item inventory model for deteriorating items with expiration date and allowable shortages, Indian Journal of Science and Technology, 7(4), 463471.

Tayal, S., Singh, S. R., \& Sharma, R. (2015). An integrated production inventory model for perishable products with trade credit period and investment in preservation technology. International Journal of Mathematics in Operational Research, Article ID 76334.

Tayal, S., Singh, S. R., \& Sharma, R. (2014). An inventory model for deteriorating items with seasonal products and an option of an alternative market. Uncertain Supply Chain Management, 3(1), 69-86. 
Tayal, S., Singh, S. R., Chauhan, A. \& Sharma, R. (2014). A deteriorating production inventory problem with space restriction, Journal of Information \& Optimization Sciences, 35(3), 203-229.

Tayal, S., Singh, S. R., Sharma, R., \& Chauhan, A. (2014), Two echelon supply chain model for deteriorating items with effective investment in preservation technology, International Journal Mathematics in Operational Research, 6(1), 78-99.

Tayal, S., Singh, S. R., Sharma, R., \& Singh A. P. (2015). An EPQ model for non-instantaneous deteriorating item with time dependent holding cost and exponential demand rate, International Journal of Operational Research, 23(2), 145-161.

Tyagi, A. P., Pandey, R. K., \& Singh S. R. (2014). An optimal replenishment policy for non instantaneous deteriorating items with stock dependent demand and variable holding cost. International Journal of Operational Research, 21(4), 466-488.

Yang, H.L., Teng, J.T., \& Chern, M.S. (2010), An inventory model under inflation for deteriorating items with stock-dependent consumption rate and partial backlogging shortages. International Journal of Production Economics, 123(1), 8-19. 